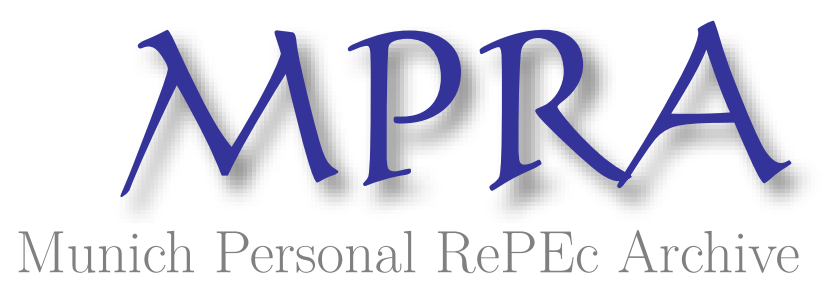

\title{
What about monetary transmission in Albania? Is the exchange rate pass-through (still) the main channel?
}

Peeters, Marga

Banka e Shqipërisë (Central bank of Albania)

March 2005

Online at https://mpra.ub.uni-muenchen.de/23671/

MPRA Paper No. 23671, posted 07 Jul 2010 09:03 UTC 


\section{WHAT ABOUT MONETARY TRANSMISSION IN ALBANIA? IS THE EXCHANGE RATE PASS-THROUGH (STILL) THE MAIN CHANNEL? \\ Marga Peeters*}

\section{ABSTRACT}

There seems to be a general perception that the exchange rate pass-through is the most important channel in the transmission process of monetary policy in Albania. This perception is questioned here in light of the altering relationships in this developing economy. A discussion on the transmission channels in the Albanian economy is followed by a study of the macro-economic relationships and pragmatic econometrics quantifying the monetary effectiveness. The results indicate that the dollar has become less important in the monetary transmission process at the benefit of the euro. There are moreover strong signs that the exchange rate channel as such is loosing its influence at the benefit of the other transmission channels, like the credit channel and most likely the wage channel.

\section{INTRODUCTION}

During the last 15 years Albania transformed from a closed and regulated economy into an open market economy. The economy recovered quite quickly from the severe recession in 1997-98 that was triggered by pyramid schemes. Already before, Albania had shown its flexibility after the government regime shift in the beginning of 
the 1990s. At that time it moved rapidly to a rather steady path in terms of both economic growth and inflation, at a speed that was much higher than in other transition countries.

These are the facts according to the data ${ }^{1}$. Next to this it is wellknown that the economy nowadays still undergoes major changes. Goods and services markets are developing, there is a gain in business and consumer confidence after the rather fresh 1997-98 crisis and the credit market is soaring. The banking sector improves slowly but steadily, as the cash economy reduces further and payments get more in line with modern payment systems in other economies. As a consequence of all these changes, the transmission channels also change continuously. In light of the strongly and rapidly moving economy the quantification of the effects of macro-economic shocks to the Albanian economy is cumbersome. For the purpose of policy this quantification is however necessary.

As it concerns monetary policy, many people in the markets as well as policy makers argue that the exchange rate channel is the strongest transmission channel in Albania. Fluctuations in the exchange rate affect the choices for domestic or foreign deposits and credits directly. Indirectly, via the imports and exports of goods and services they affect economic growth and inflation.

From a study on monetary transmission in Albania by Muço, Sanfey and Taci (2004) can implicitly be concluded that the exchange rate is no longer the most important channel during the period 2000-2003. This paper studies the details of the monetary policy transmission process further ${ }^{2}$. We argue that next to the exchange rate channel, the deposit, credit and wage channels (also) have altered during the last years. If these other channels got more well-developed and gained sufficiently in influence, they may have become as important as the exchange rate channel. Here we want to test the hypothesis that the exchange rate is the most important transmission channel in the monetary policy process.

We keep in mind that relationships between crucial factors may be continuously changing in that they become more complex and stronger while the economy converges to a fully-fledged market 
economy. To say it in Lucas' critique terms, we try to account for the fact that the reaction coefficients of the relations are not constant as policy and other structural changes have altered and are altering them $^{3}$. Sophisticated econometric analysis is not feasible in view of the short data series, so being pragmatic is at place.

The outline of the paper is as follows. Section 2 sketches in broad lines the monetary transmission process in general and the monetary transmission process in Albania in particular. Section 3 discusses the crucial chains in the channels of the transmission process for Albania and points at changes in these bilateral relationships by means of cross-correlation analyses. Section 4 presents some pragmatic VARanalyses. Section 5 summarizes and concludes prudently.

\section{THE MONETARY TRANSMISSION PROCESS}

\subsection{Monetary Transmission In Global Lines}

The monetary transmission process is stylized shown in Graph 1. At the top there is the main instrument of the monetary authority, the monetary policy rate. In many countries this rate is the repo rate. Monetary policy is eased in case this rate decreases, while on the contrary, monetary policy is tightened in case this rate increases. Monetary authorities with a strategy of inflation targeting will aim at affecting the growth rate of the consumer price index, i.e. inflation. Inflation appears in the lower part of Graph 1. The transmission from movements in the monetary policy rate to movements in inflation flows through different channels. The more effective monetary policy is, the more precise and the more rapidly the monetary authority is able to steer the inflation towards a desired rate by means of the policy rate. The degree of effectiveness depends among others on the speed of the transmission via the channels between the monetary policy rate and inflation.

We distinguish here three main channels. The first channel on the left hand side in Graph 1 is the exchange rate channel. The second channel on the right hand side is the deposit and credit channel. The third channel below in Graph 1 is through wages. Changes in 
the monetary policy rate can directly affect the exchange rate, and the volumes of deposits and loans. Usually an increase (a decrease) in the policy rate will lead to an appreciation (a depreciation) of the domestic currency. At the same time, a change in the policy rate will lead to a change in the same direction in the deposit and credit rates. So, an increase (a decrease) in the policy rate leads to an increasing (a decreasing) in the deposit and credit rates.

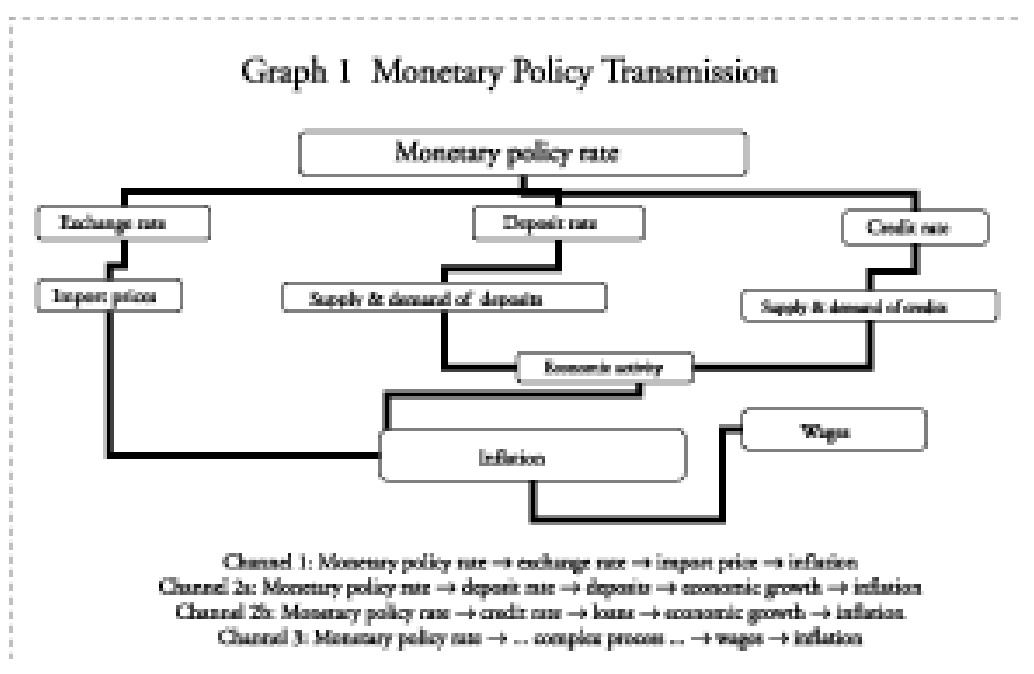

The pass-through of the policy rate via the exchange rate - i.e. channel 1 - further feeds through the import prices onto inflation. An appreciation (a depreciation) of the domestic currency makes foreign goods and services cheaper (more expensive), so import prices will decrease (increase) and this influences the domestic consumer prices negatively (positively). So inflation will fall (augment).

The pass-through from the monetary policy rate to inflation via the credit and deposit rates is through the demand and supply of both loans and deposits, respectively. As a reaction to higher (lower) credit and deposit rates loans will fall (augment) whereas deposits will augment (fall). Changes in loans and deposits imply changes in broad money growth, e.g. M2 or M3. The pass-through of this channel leads via different ways to changes in the real economy and therefore in economic growth. Monetary tightening (easing) via this channel 
will lead to lower (higher) demand pressure and may therefore lead to a downward (upward) pressure on consumer prices. Inflation may thus fall (augment) ${ }^{4}$.

The third channel is the most difficult to explain. It generally holds that wages affect consumer prices. After all, higher wages per unit product lead to higher consumer prices. Lower wages per unit product will on the contrary not always directly lead to lower consumer prices as profit margins can be increased.

Moreover, the channel from wages to inflation also depends on labour productivity that depends on economic growth. A direct influence of prices on wages, the so-called wage-price spiral, may also exist. In addition, the channel from the monetary policy rate to wages is also complex. The wage channel from the monetary interest rate to inflation via wages is nevertheless in most economies non-negligible. So, we emphasize here its importance but remain somehow vague.

Looking from the bottom of Graph 1 to the consumer price, we conclude that the consumer price is influenced by (1) import prices that are affected by the exchange rate (2) demand pressure and (3) wage pressure. Next to these determinants indirect taxes and profit margins will play a role. In this paper we will however concentrate on the first three factors mentioned.

\subsection{Some Remarks concerning Monetary Transmission in Albania}

The Albanian economy is a small open economy. This implies that developments in the world economy, in particular in those countries that trade with Albania, strongly influence the Albanian economy. For this reason the exchange rate channel will be influenced by foreign factors in addition to monetary policy. These foreign influences may even overshadow monetary policy decisions in Albania.

Concerning Albanian trade, imports are much more sizeable than exports. The share of exports in the balance of payments is rather low. For this reason the pass-through of the exchange rate on export prices onto the volume of exports and economic growth will be limited. 
People in Albania with private savings can invest their money in bank deposits or treasury bills. Alternative investments like equity or bonds are rare. Financial markets are underdeveloped. For this reason deposits may be relatively inelastic. So, although deposit rates can react to monetary policy changes, changes in the volume of deposits in reaction to changes in the deposit rates may be insignificant. This implies that due to a tight (loose) monetary policy deposit rates may increase (decrease) but the volume of deposits may remain unchanged.

The extent of loans in domestic currency in Albania is still limited. So, although credit rates can react to monetary policy changes and the impact on the demand or supply of loans might be strong, the overall impact through this credit channel is expected to be small. This implies that a more tight (loose) monetary policy may lead to higher (lower) credit rates, and even less (more) demand for loans whereas in absolute terms the change in loans is small. The size of the growth in loans is however indicative for inflation. Concerning the wage channel we emphasize the high level of unemployment and weak labour unions in Albania. Wage pressure may for these reasons be low in comparison with developed countries. So, the channel from wages through inflation may be weak. In sum, according to the general observations mentioned above, the exchange rate, credit and deposit channels as well as the wage channel could still be relatively weak. To obtain more solid evidence the next section presents a data analysis of the Albanian economy. We will question in particular the hypothesis that the exchange rate channel is stronger than the other channels. In order to put this hypothesis to the test the effects of the separate channels are quantified. This will give us insights into the relative importance of each of the three main channels along with their improvements in time.

\section{SIGNS OF CHANGE IN THE TRANSMISSION CHANNELS IN ALBANIA}

\subsection{A changing relationship between the exchange rate and inflation}

Recently the LEK strongly appreciated vis-à-vis the dollar. In October 2000 the LEK/dollar exchange rate peaked at more than 
150 LEK per dollar. Since this moment the dollar depreciated more than 35\% to far less than 100 LEK per dollar. In the same line, but during a shorter period and less strongly, the LEK appreciated vis-àvis the euro. Since the peak in May 2003 of more than 140 LEK per euro the depreciation of the euro exceeded $10 \%$.

One would expect that the appreciation of the LEK would have depressed inflation. After all, imported goods and services became cheaper. Given the large extent of imports in the Albanian economy consumer price increases should have been lower. Remarkably however, this is not observed. Inflation remained quite constant, as Graph 2a shows. These results corroborate previous findings in Albania for the years 1990-2000 where appreciations of the domestic currency were not reflected in inflation whereas depreciations induced a higher inflation (see Kolasi, Çeliku, Harshova, 2001).

From Graph 1 it follows though that the LEK/euro-exchange rate moved quite in line with inflation before 2003. The appreciation of the LEK from 1998 until about 2000 was accompanied with a lower inflation, whereas from 2000 until 2003 the LEK depreciated and inflation augmented. Thus, at first sight the relationship between the exchange rate and inflation seems to have reversed in 2003.

This is corroborated in Graph 2b. This Graph presents for periods of three years the correlations between the exchange rate and inflation. For example, it follows from the first bar that the contemporaneous correlation for the years 1998-2000 was more than $80 \%$. For the period 1999-2001 the second bar shows a correlation of almost $80 \%$. For $2000-2002$ the correlation is still positive, but much lower with about $50 \%$. The fourth bar shows a sign change. For this period 2001-2003 the correlation is lower than $-40 \%$.

Subsequent bars show for the same windows of periods the correlations of the exchange rate with inflation 1, 2 until 5 months later. This is interesting as the exchange rate may not affect inflation in the same month, but after some time. It follows that for the period 1998-2000 the exchange rate affected inflation after 5 months with more than $60 \%$. On the contrary, for the period 2001-2003 the correlations remain negative even after 5 months. So the appreciation 
of the LEK did not influence inflation negatively, not even after 5 months.

The same results -not shown here- hold for the exchange rate of the LEK vis-à-vis the dollar. The change in the relationship occurs however earlier. For these changes in both exchange rates several explanations may hold. One of the explanations could be given by the higher productivity in the tradeable goods sector. This is the so-called Balassa-Samuelson effect that holds for countries that are catching up with more developed countries. See for a study on the Albanian currency appreciation Olters (2005). Another explanation might be money laundering. Here we only conclude that the relationship between exchange rate and inflation seems to have altered and we try to find more evidence on possible changes in the other monetary transmission channels in Albania.

\subsection{The more prominent role of M2 since 2000}

According to econometric analyses on monetary transmission by Muço, Sanfey and Taci (2004) there is a significant change observable in 2000. In this year the Bank of Albania started using indirect instruments for monetary policy instead of direct instruments. Until August 2000 the Bank set deposit rates directly and imposed credit ceilings. Since September 2000 the Bank controls the repo rate and can therefore influence the deposit and credit rates only indirectly, like indicated in Graph 1. Muço et al use a VAR-model where remittances, the growth of money supply measured as M2, the annual growth rate of the LEK/USD-exchange rate, inflation and the growth rate of the real trade balance are included. For the period from January 1993 until August 2000 an important part of the variance in inflation is after 12 months due to the exchange rate. For the period from September 2000 until December 2003 it is M2 that explains most of this variance of inflation. Table 1 shows the full variance decomposition of inflation for these subperiods. According to these results the channel through M2 has thus become stronger than the exchange rate channel after 2000. Interesting is that these findings can be fully in line with the change in relationship between the exchange rate and inflation as discussed in section 3.1. After all, 
in case there was a structural change in this relationship around 2000 the exchange channel as such may have become less strong at the benefit of the other channels, e.g. the second (via M2 and demand pressure) channel as shown in Graph 1.

Table 1 Vuriance Decomposition of Inflation after 12 months

\begin{tabular}{|l|r|r|r|r|r|}
\hline & Rernittances & M2 & Exchange Rate & Inflation & Trade Balance \\
\hline 1993.2000 & 0.9 & 0.9 & 23.9 & 64.5 & 29.8 \\
\hline 20002003 & 29.4 & 35.6 & 1.7 & 27.5 & 5.8 \\
\hline
\end{tabular}

3.3 Changes in the relationships policy rate $\&$ deposit rate and deposit rate \& deposits

As said before, the deposit rates were no longer set by the central bank since September 2000. So the relationship between the rates changed due to a policy change. Since September 2000 the deposit rates may react to movements in the monetary policy rate. This decision had to be made by each of the commercial banks individually. In order for monetary policy to be transmitted through this channel the deposit rates should move in line with the monetary policy rate.

Graph 3a shows the deposit rates for 3-, 6-and 12-months deposits along with the policy rate. Except for a major drop of 4 percentage

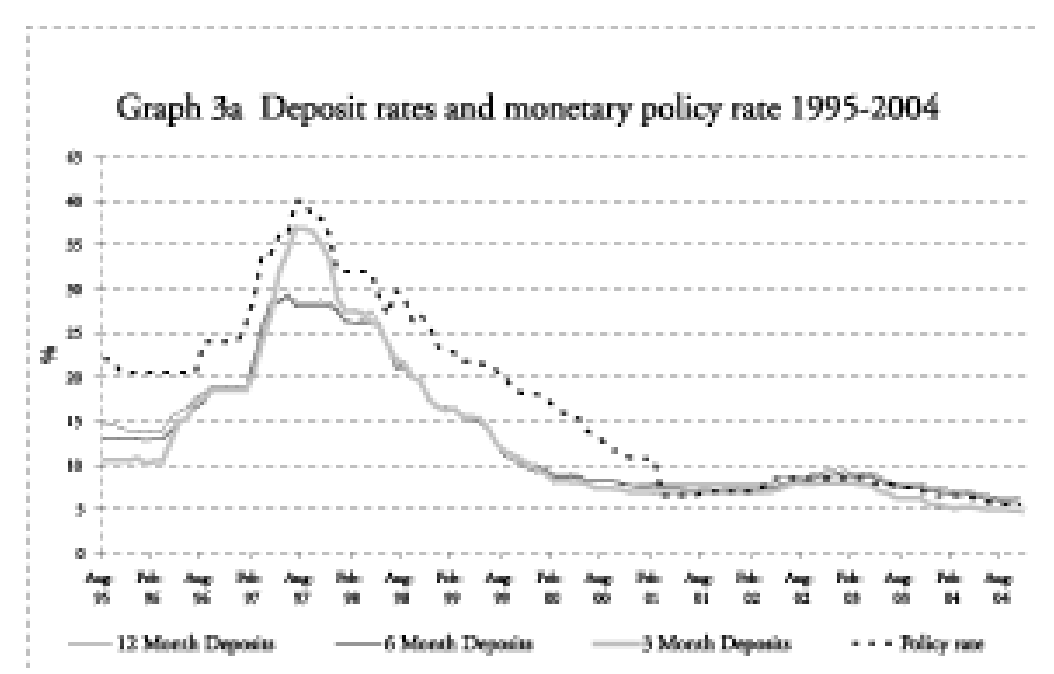


points from $10.5 \%$ to $6.5 \%$ in the monetary policy rate in 2001 , the rates moved nicely in line with the monetary policy rate. The correlation between the 6-months and the policy rates is strongest, with $66 \%$. So this chain in the transmission process seems at work.

In order for monetary policy to be effective via the deposit rate, the demand for and supply of deposits should react accordingly to a monetary easing or tightening. If not, the deposit channel would be dead.

Graph $3 \mathrm{~b}$ shows the deposit rates and new deposits by maturity. It follows that the easing of monetary policy since 2002 and the accordingly lower deposit rates induced less new long term deposits. This happened in particular in 2004. So, apparently people invested their money elsewhere. From this we draw the conclusion that lately a reaction from the demand and/or supply of deposits or deposit rates is apparent. So, here the deposit rate channel seems functioning.

\section{Graph 3b New Deposits and Deposit Rates by Maturity}

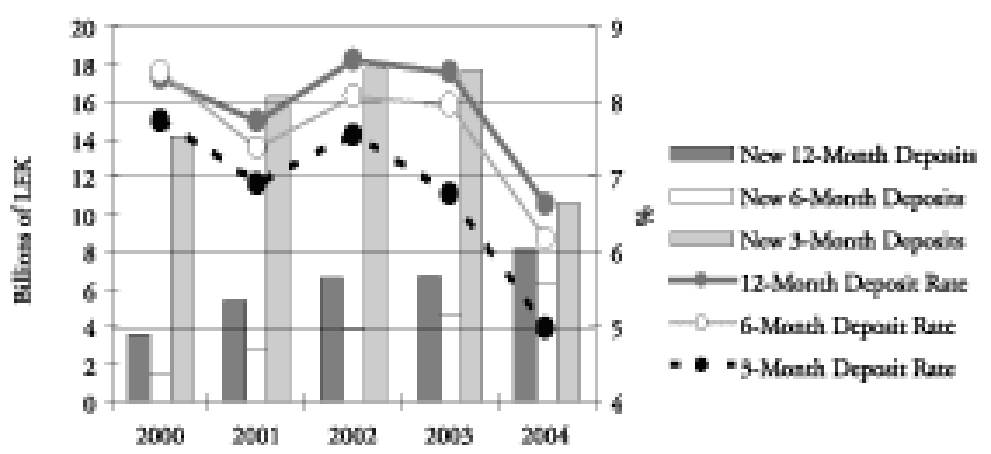

3.4 Changes in the relationships policy rate \& credit rate and credit rate \& loans

In a similar vein, a credit channel in the monetary policy transmission process would work in case the credit rates react to 
monetary policy changes and the demand and/or supply of loans would react to movements in the credit rates. From the Graphs 4 and 5 follows that these relationships are more difficult to grasp.

Graphs $4 \mathrm{a}-4 \mathrm{~b}$ show the monetary policy rate and the credit rates for each month and each Albanian commercial bank. The rates are monthly averages. There is a line drawn through the scatter plot indicating the "average" direction. So, e.g. Graph 4a shows for the period 1995-2004 a positive line. One could conclude that there is on average a positive relationship between the monetary policy rate and the credit rates. This type of relationship would be according to our expectations. Graph 4b then presents the data points for 2004. Here it follows that for 2004 there is on average a nearly flat or no relationship. Monetary policy eased further in this year to quite low levels while the credit rates did on average not follow.

Nevertheless, we may conclude on the basis of the overall results here that the relationship between the monetary policy and credit rates is on average not wrong in order for monetary policy to be effective in the credit channel. But not all loans followed the policy rate moves, as can be concluded also from Table 2 where the average rate per maturity is presented. Probably there are other determining factors than the monetary policy rate for the credit rates.

Table 2 Average Mon etary Policy and Credlit Rates per Maturity
\begin{tabular}{|l|r|r|r|r|r|}
\hline Yeat & $\begin{array}{r}\text { Monetary } \\
\text { Policy Rate }\end{array}$ & $\begin{array}{r}\text { 6-months } \\
\text { Credit Rste }\end{array}$ & $\begin{array}{r}12 \text {-months } \\
\text { Credit Rate }\end{array}$ & $\begin{array}{r}1-3 \text { year } \\
\text { Credit Rate }\end{array}$ & $\begin{array}{r}\text { Mote than 3 } \\
\text { year Credit rate }\end{array}$ \\
\hline 2001 & 7.4 & 18.1 & 16.4 & 163 & 15.8 \\
\hline 2002 & 82 & 16.5 & 163 & 16.4 & 15.9 \\
\hline 2003 & 7.7 & 15.0 & 14.5 & 163 & 14.6 \\
\hline 2004 & 59 & 13.5 & 15.5 & 15.6 & 14.5 \\
\hline
\end{tabular}

Graphs $5 \mathrm{a}-5 \mathrm{~d}$ present the relationships between the credit rates and loans for each of the years 2001 up to 2004. In order for monetary policy to be effective, the relationships should be negative as lower (higher) rates should increase (reduce) the demand for credit. It follows that in 2001 and 2003 the average sign is accordingly. We should here however be careful as a linear relationship does not seem appropriate. In 2002 the sign is positive. The lower rates did apparently not induce more loans. Like the monetary policy and 
credit rates in Graph 4b, there in hardly a relationship in 2004. One could conclude that the further easing of monetary policy did not trigger a further lowering of the credit rates for most of the banks, so neither was there a higher demand for loans.

Consequently, the working of the credit channel is somehow troubled. For a deeper study with in broad lines similar findings, see Luçi and Vika (2005).

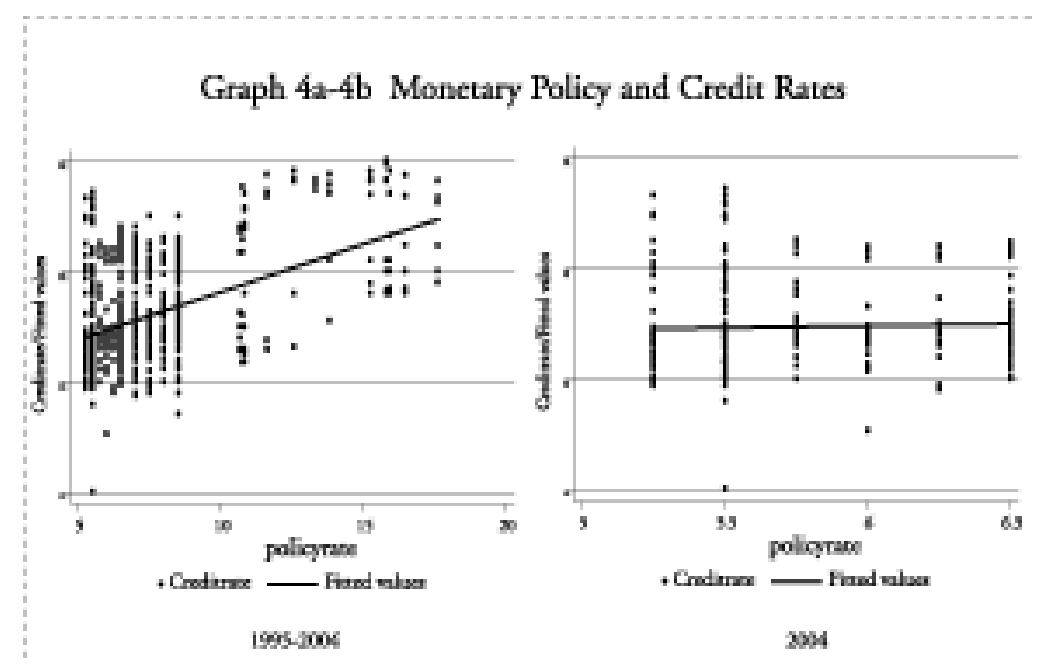


Graph 5a-5d Credit Rates and the Volume of Loans (First differences and annual growth rates, respectively)
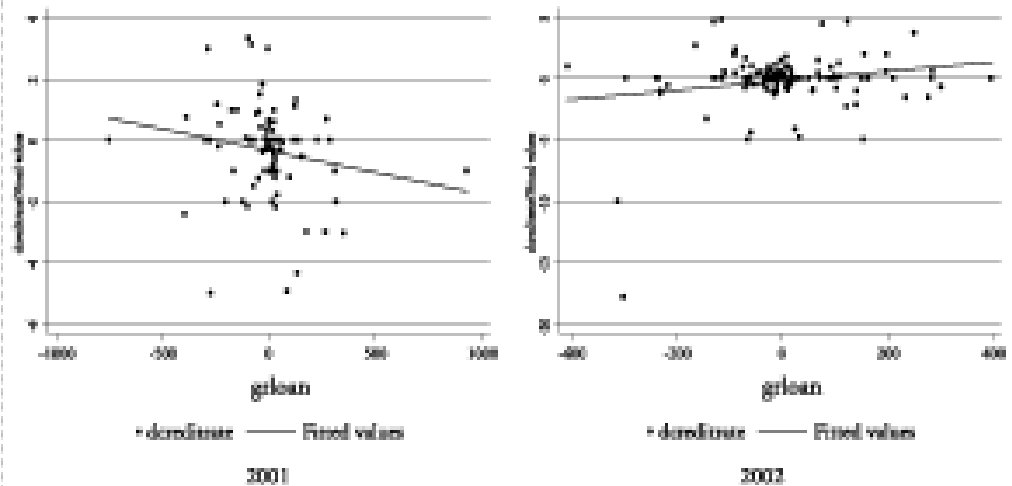

2001

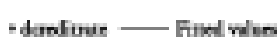

2002

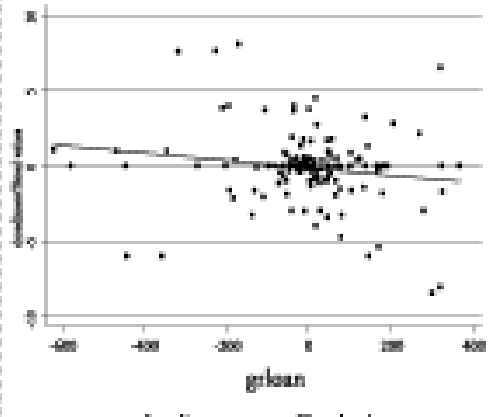

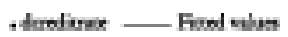

2003

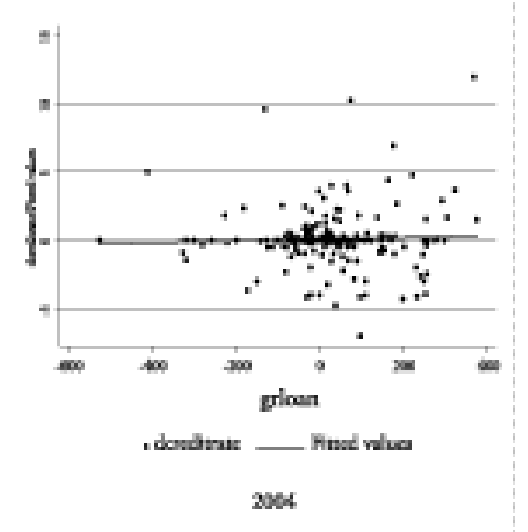




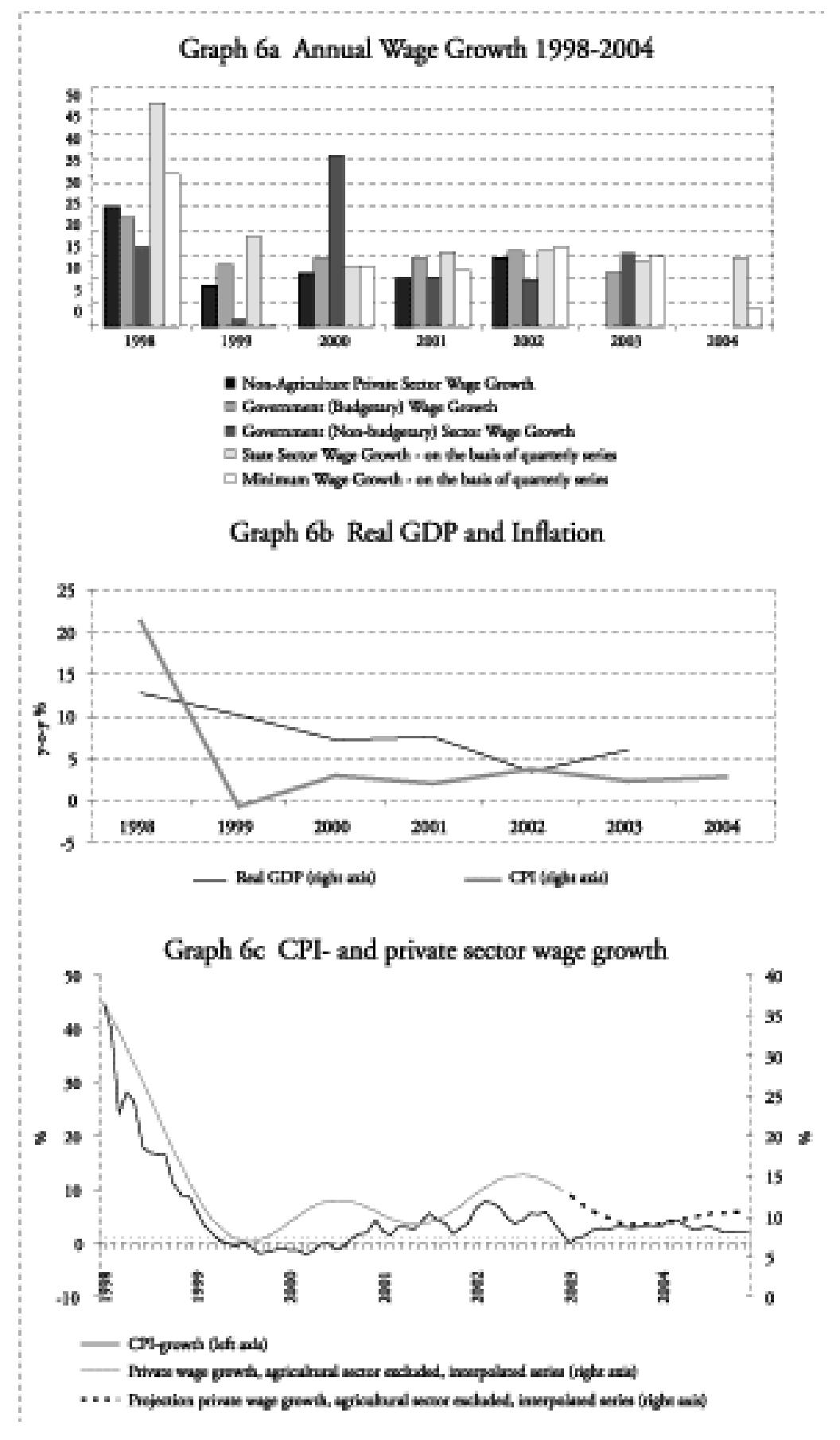




\subsection{More Wage and Demand Pressure?}

The lack of reliable, detailed and timely data on wages and economic growth makes it difficult to draw strong conclusions on the relationships between wages and inflation and between economic growth or demand pressure and inflation. Unfortunately we are only able to present Graph 6a-6c here.

In Graph 6a annual wage growth rates are presented. Five different sectors are provided: (i) the non-agricultural private sector (ii-iii) the government sector split into budgetary and non-budgetary (iv) the state sector and $(\mathrm{v})$ the minimum wage. In terms of employment the government accounts for about $20 \%$. The government and the nonagricultural private sector account for less than $30 \%$ in 2000 and about $40 \%$ in 2002 . Assuming that the government sector mainly accounts for services that are about $15 \%$ of the consumer price basket, wage increases in this sector will be a non-negligible cost push for the full basket of consumer prices. The CPI-basket consists for more than $40 \%$ of food, so the fully absent agricultural wage developments would be most important for our purposes here.

Stressing again all uncertainties that we encounter, and even with the lack of private sector wages for 2003 and 2004, we tentatively say that developments in wage growth and inflation are more in line with each other in 2001-2003 than in the earlier years. The peak in inflation in 1998 does not seem to result from excessive (private sector) wage growth. Moreover, in 2000 and also 2001 average wage growth was relatively high, whereas it is not reflected in the development of consumer prices.

Graph 6c shows the growth of the annual wage series for the non-agricultural private sector interpolated into a monthly series, along with the development of monthly year-on-year inflation. For the years 2003 and 2004 an average wage growth of $10 \%$ is projected with a view to the observed developments in the government sector and minimum wages. According to this Graph wage growth has a quite similar development as inflation. Whether or not any wage pressure is transmitted into consumer prices, and if yes, whether or not this pressure becomes stronger as expected in a developing 
economy with strong productivity increases according to Balasso and Samuelson, can however only be statistically tested once more data will become available.

Apart from this cost-push linkage, the other positive linkage from wages to inflation is via the demand side. As a consequence of higher wages consumers have more purchasing power. So consumer spending can augment. Under the precondition that the supply of goods and services is restrictive, prices would then move upwards. For Albania this channel did not seem strong during the recent years. The quite reasonable economic growth for a developing economy of $6 \%$ in 2003 was not accompanied with a higher inflation. For the years around the economic crisis in 1998 it may however have been strong as wages in some sectors of the economy strongly increased, causing inflation but at the same time helping economic growth to recover fully from the through in 1997 of $-10.2 \%$.

So, although it is scientifically not responsible to draw any conclusions on the few data observations we have here, our economic intuition tells us that there is an important wage channel that very likely affects inflation whereas demand pressure may (still) be quite absent.

\section{PRAGMATIC ECONOMETRIC ANALYSES}

Quantitative evidence for the relative importance of each of the channels in the monetary policy transmission process is obtained by VAR-analyses as shown in the Graphs $7 \mathrm{a}-7 \mathrm{~b}$. In these analyses the monetary policy rate, the exchange rate, the volume of deposits, the volume of credits and inflation are included. The exchange rate used is either the LEK/euro or the LEK/dollar. Graph 7a includes the LEK/euro and Graph 7b the LEK/dollar. The VAR-models are estimated for the samples 1998-2000, 1999-2001, 2000-2002, 20012003 and 2002-2004. The main results are the following.

Graph 7a shows in the full right part that for the sample 20022004 the variance of inflation was mainly explained by inflation itself and credits, and to a minor extent deposits, the LEK/euro rate and 
the monetary policy rate. The middle part of this Graph for the sample 2000-2002 shows a completely different picture. Here it is the exchange rate that mainly accounts for the variance of inflation. From this follows that the exchange rate with the euro has become less important at the benefit of credits. The impact of the different transmission channels concerning inflation has thus fully changed.

In Graph 7b - as said before - it is the exchange rate with the dollar instead of the exchange rate with the euro that is included. Looking at the share of this exchange rate it follows that the dollar hardly explains the variance of the inflation in the recent period. Table 3 shows that the fit is also considerably lower. The dollar has thus lost power, even earlier and to a stronger extent than shown for the euro in Graph 7a.

Table 3 Adjusted $\mathrm{R}^{2}$ for the inflation equation in the VAR-analyses

\begin{tabular}{|l|r|r|r|r|r|}
\hline & $98-00$ & $99-01$ & $00-02$ & $01-03$ & $02-04$ \\
\hline VAR with L.EK/euro & 0.97 & 0.87 & 0.89 & 0.80 & 0.87 \\
\hline VAR with L.E./dollar & 0.98 & 0.85 & 0.82 & 0.70 & 0.84 \\
\hline
\end{tabular}

Analyses including both the euro and the dollar - that are surpressed here - show that the euro is much more important than the dollar. During the most recent years the influence of the dollar has vanished quickly. The euro accounts for five times as much as the dollar. A likely explanation is here that the introduction of the euro notes and coins in 2001 in the EMU facilitated Albania using this currency with most trading partners.

The drawback of the VAR-analyses is that they only provide information on the relative importance for those factors included. One of the "absent" factors is wages. Wages are not included as it seems econometrically irresponsible to use the monthly interpolated series that hardly contain fluctuations (as shown in Graph 6c). The absence of wages may however explain the major part of inflation that is still not explained, or otherwise stated, explained by itself according to the large upper parts in Graphs 7a-7b.

Being naughty and including the private wage series nevertheless - where the results are of course not shown here - evidently shows 
that a much smaller part of the variance in inflation is explained by inflation. For 2000-2002 wages absorb at least 10\% where this share depends on the type of exchange rate included. For the periods thereafter we can unfortunately not perform this test at all as we do not even have the annual wage figures for the private sector (as Graph 6c also indicates).

Concluding by looking once more at Graphs 7a-7b, we can say that there are major changes in the monetary transmission channels. The moving shares over the five samples indicate that there are strong shifts in these transmission channels and that these shifts point at a diminishing role of the exchange rate at the benefit of the credit channel. Our intuition and finger exercises with the scarce amount of wage observations furthermore force us to conclude that the wage channel should not to be neglected. 


\section{Graph 72-7b Variance Decomposition of Inflation}

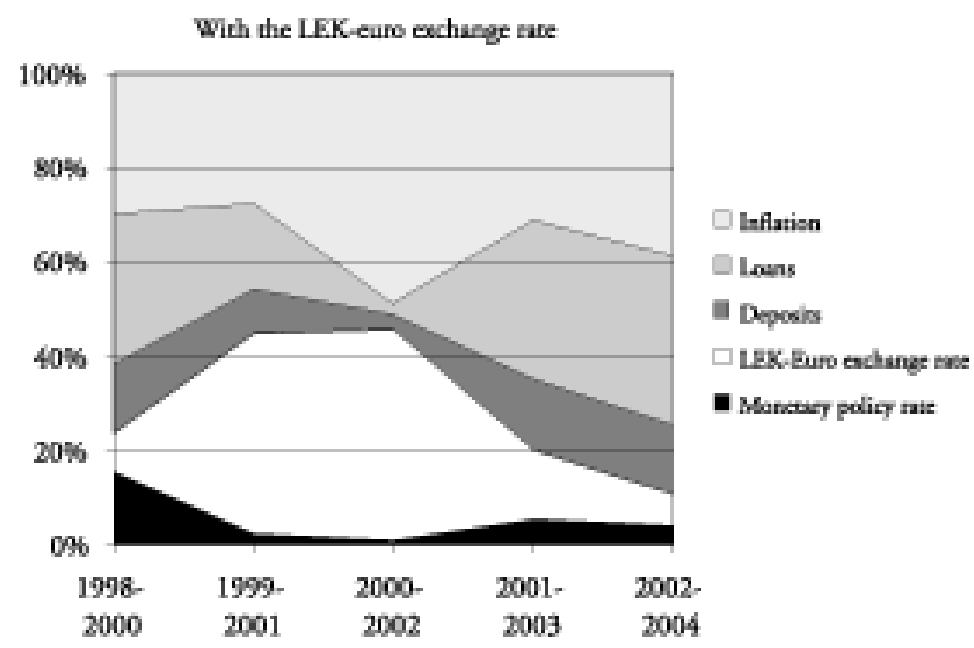

With the 1.EK-dollar exchange nate

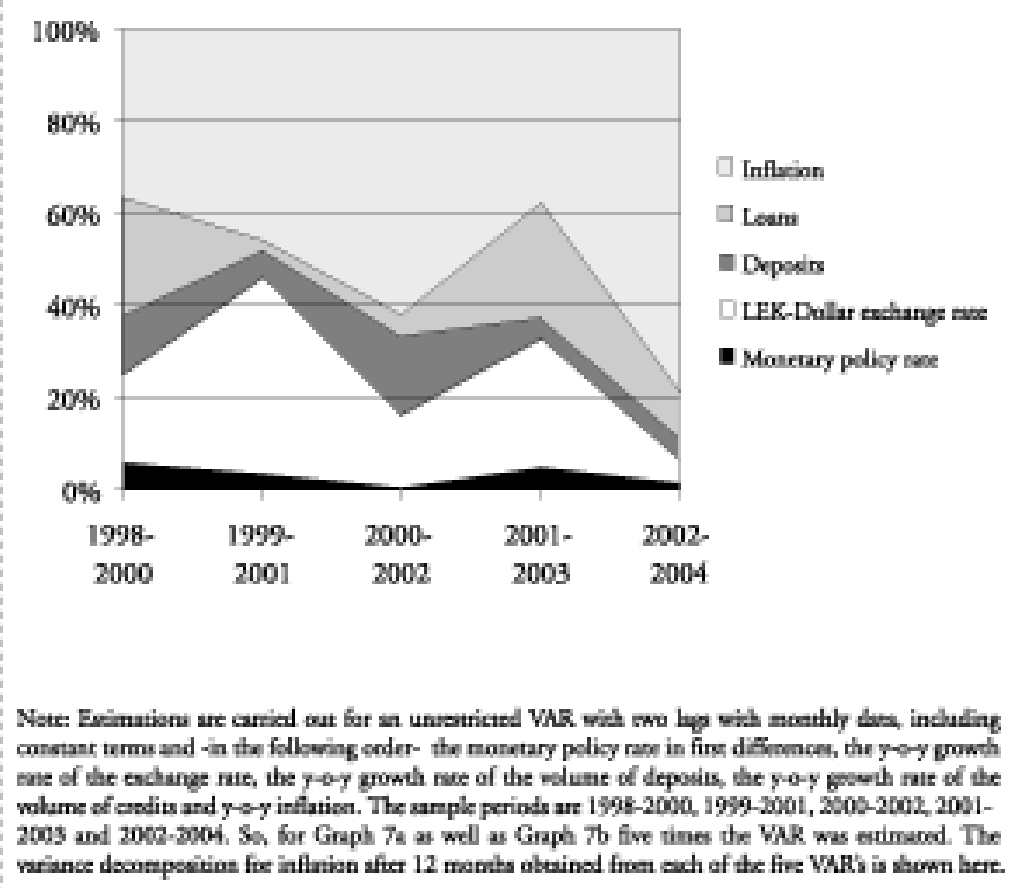




\section{SUMMARIZING AND CONCLUDING REMARKS}

Before drawing final conclusions we stress again the pragmatic character of the presented analyses in this paper. The results should be interpreted with caution in view of the relatively short samples, the rapid developments and major changes in the Albanian economy.

On the basis of correlation analyses of the main relationships in the transmission channels in Albania, and according to the VARanalyses, there are strong indications that the role of the dollar in the Albanian economy is diminishing at the benefit of the euro. There are also indications that the relationship between the LEK/euro exchange rate and domestic inflation is changing.

The LEK appreciates whereas at the same time inflation does not diminish significantly. This, along with the signs of a stronger credit channel, and very likely also a strong wage channel, seems to indicate that the exchange rate channel is loosing power in the monetary transmission process at the benefit of the other channels.

The conclusion concerning the diminishing role of the exchange rate channel at the benefit of money channels is fully in line with the findings of Muço et al. (2004).

For the conduct of monetary policy these findings imply that the attention for the exchange rate ought to be shared among the exchange rate, credit and wage developments. As appropriate data on wages are fully lacking for Albania's most important sector in view of the consumption basket -i.e. agriculture- and wage data for the private sector in general are at a low frequency and lagging behind, there is an urgent need to fill this major statistical gap.

In the near future monetary transmission in Albania may be expected to feed through more channels due to all kind of new developments, through channels more strongly, and at the same time also at a more rapid speed. For (monetary) policy making more detailed, timely and better statistical evidence for facilitating a more solid basis would therefore be warmly welcomed. 


\section{REFERENCES}

Darvas, Zsolt, 2001, Exchange Rate Pass-Through and Real Exchange Rate in EU Candidate Countries, Discussion Paper No. 10/01, Economic Research Center of the Deutsche Bundesbank.

Kara Hakan, Hande Kücük Tuףer, Ümit Özlale, Burc Tuğer, Devrim Yavur, Eray M. Yücel, 2005, Exchange Rate Pass-Through in Turkey: Has it Changed and to What Extent?, The Central Bank of the Republic of Turkey.

Kolasi, Gramoz, Evelina Celiku and Gent Harshova, December 2001, Inflation Trend in Albania during the Previous Decade: An Empirical Outlook, Economic Bulletin pp. 36-47, Bank of Albania.

Luç, Erjon and Ilir Vika, 2005, The Bank Lending Channel in Albania: Evidence from Micro-Level Data, paperpresented at the Workshop on Monetary Policy Issues and Inflation Forecasting, Tirana.

Muço Marta, Peter Sanfey, Anita Taci, 2004, Inflation, Exchange Rates and the Role of Monetary Policy in Albania, European Bank for Reconstruction and Development Working Paper No. 88.

Olters, Jan-Peter, 2005, Is Inflation too Low in Albania?, paper presented at the Conference Central Banking in the Time of Integration organized by the Bank of Albania, March 2005 


\section{ENDNOTES}

* Marga Peeters: resident IMF Monetary Policy Advisor. Address: Monetary Policy and Research Departments, Sheshi Skënderbej, No. 1, Tirana, Albania, mpeeters@bankofalbania.org, hmmpeeters@wanadoo.nl, marga-mobiel@imail.nl. The views expressed do not necessarily reflect the views of the International Monetary Fund or the Bank of Albania. I want to thank Erjon Luçi, Evelina Çeliku and Gramoz Kolasi and participants at the Conference Central Banking in the Time of Integration for their comments. All views and errors are mine.

${ }^{1}$ We take the statistical data from INSTAT and other Albanian sources as given, so questioning the data is beyond the scope of this paper.

${ }^{2}$ Main differences with the study of Muço et al are that we (i) include the LEK/euro exchange rate instead of the LEK/USD exchange rate (ii) include credits and deposits instead of M2 (iii) experiment with wages (iv) include the monetary policy rate (v) use a different order of the variables (vi) update the sample and (vii) estimate the VAR-models for more sub-periods.

${ }^{3}$ In fact, we perform standard VAR-analyses on a series of short samples. Other econometric techniques, like Kalman filters (as in Darvas, 2001, and Kara et al, 2005), are more suitable but not feasible for Albania due to the low-frequency data and shortness of the samples.

${ }^{4}$ Economic growth will also depend on exports that depend among others on export prices, and the development of wages. The effects of export prices - that should go in the left hand side of Graph 1- and wages -below in Graph 1- on economic growth are not present in Graph 1 as it would make the picture fuzzy. 